\title{
Effect of physical training on insulin resistance and alpha-glucosidase activity in early stage symptom of type 2 diabetic mice
}

\author{
Toshihiro Miura', Takuaki Nishida ${ }^{1}$, Eriko Isihara', Torao Ishida ${ }^{2}$ and Keilchiro Tanigawa ${ }^{1}$ \\ ${ }^{\prime}$ Department of Clinical Nutrition, Suzuka University of Medical Science, Faculty of Health Science, 1001-1 Kishioka-cho, \\ Suzuka, Mie, 510-0293, Japan. \\ ${ }^{2}$ Hi-tech Recerch Center, Suzuka University of Medical Science, 1001-1 Kishioka-cho, Suzuka, Mie, 510-0293, Japan.
}

(Received 16 November 2000; and accepted 18 January 200I)

\begin{abstract}
Restricted diet and physical training (PT) are the first treatments for early stage symptom of type 2 diabetes. We studied the effect of PT on insulin resistance in pheripheral tissues and alpha-glucosidases in small intestine of KK-Ay mice, an animal model of type 2 diabetes. The blood glucose and plasma insulin level in KK-Ay mice were significantly decreased after 3 weeks of PT when compared with control group (no-exercise). PT caused decrease in insulin resistance, which may be beneficial, for insulin tolerance. However, PT had little, if any, effect on alpha-glucosidase activity in small intestine of KK-Ay mice.
\end{abstract}

Insulin resistance in peripheral tissues and increased glucose uptake in small intestine are known as the major pathogenic factors of type 2 diabetes, in which glucose-induced insulin secretion may also be impaired in beta cells. Restricted diet and physical training (PT) are the initial cures for early stage of type 2 diabetes. Since alpha-glucosidases in small intestine hydrolyse disaccharide to monosaccharide, therapeutic agents to inhibit the alpha-glucosidase of small intestine have been used for the treatment of type 2 diabetes patients in recent years $(1,2,6,8,9,13$, 15). However, there is no experimental evidence of interaction between alpha-glucosidases and exercise. The purpose of this study, therefore, is to examine the interaction between PT and alphaglucosidases using type 2 diabetic animal model. Animals. Male KK-Ay mice (Clea, Tokyo, Japan) on early stage of type 2 diabetes condition (6-11 weeks old) were used. Under non-fasting, those with blood glucose levels above $200 \mathrm{mg} / \mathrm{dL}$ were considered to be diabetic and used in this

Correspondence to T. Miura at the above address, Tel: 0593-83-8991 (Ext. 2216); Fax: 0593-83-9666; Email:miura@suzuka-u.ac.jp study. These mice were housed in an airconditioned room at $22 \pm 2^{\circ} \mathrm{C}$ with a $12 \mathrm{~h}$ light and $12 \mathrm{~h}$ dark cycle. The animals were kept in the experimental animal room for 7 days with free access to food and water. For the determination of blood glucose levels, blood samples $(20 \mu \mathrm{g})$ were withdrawn from the cavernous sinus with a capillary glass tube.

Exercise. For PT studies, KK-Ay mice were physically trained on a motorized treadmill (Muromati Kikai Co. Ltd Osaka Japan) for $120 \mathrm{~min}$ ( $5 \mathrm{~m} / \mathrm{min}, 7 \%$ grade) every day (7). The studies started between 13:00-14:00 pm.

Alpha-Glucosidase Activity. After overnight fasting, mouse small intestine was excised, mucos membrane was removed on a slide and homogenized individually with Potter-Elvehjem homogenizer. Alpha-glucosidase activity was assayed by the method of Dahlqvist with some modifications (4). Scrose, maltose $(50 \mathrm{mM})$ and isomaltose (5 $\mathrm{mM}$ ) were incubated with diluted enzyme. The reaction was terminated by placing in a boiling water bath for $3 \mathrm{~min}$ and glucose content was determined. 
Determination of Blood Glucose. Blood glucose levels in animals were determined by the glucose oxidase method (14).

Statistical Analysis. All the data were expressed as means \pm S.E.M. and Student's $t$ test was used for the statistical analysis. The values were considered to be significantly different when the $P$ value was less than 0.05 .

\section{Effect of PT on blood glucose level in $K K-A y$ mice}

In a preliminary study, normal mice were trained at different speed $(0,5,10$ and $15 \mathrm{~m} / \mathrm{min})$ and found that the exercise at $5 \mathrm{~m} / \mathrm{min}$ caused moderate effect on diabetic KK-Ay mice (data not shown). Fig. 1 shows changes in blood glucose levels during the course of PT in KK-Ay mice and those in KK-Ay mice without PT (control group). PT caused a significant decrease in blood glucose levels when compared with the levels in the control group $(P<0.05)$.

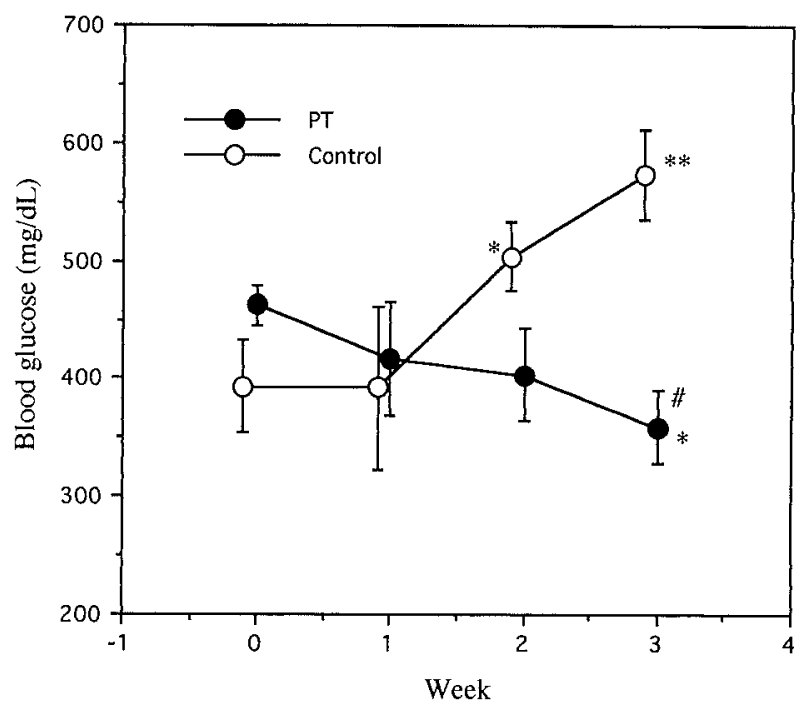

Fig. 1 Effect of exercise training on blood glucose level in KK-Ay mice. KK-Ay mice were run on a motorized treadmill for $120 \mathrm{~min}(5 \mathrm{~m} / \mathrm{min}, 7 \%$ grade). On 0, 1, 2 and 3 weeks, blood samples were collected. Each point indicates the mean \pm S. E. M. from 4 - 6 mice. Significantly differece $(\# P<0.01)$ between the PT group and the control group. Significantly difference $(* P<0.05, * * P<0.01)$ between the values before and after $\mathrm{PT}$.

\section{Insulin tolerance test}

The effect of PT on insulin tolerance test are shown in Fig. 2. A significant decrease in insulininduced blood glucose level was observed in PT group as compared to the corresponding level. The glucose level after overnight fasting in the PT group was significantly $(P<0.05)$ lowerer than that in the control group.

Effect of Exercise training on alphaglucosidases in $K K-A y$ mice

As shown in Fig. 3, activities of alphaglucosidases (maltase, sucrase, isomaltase) in the PT group were not significantly different from the corresponding values in the control group.

The present study clearly showed the effect of exercise training on blood glucose and insulin resistance in KK-Ay mice. Blood glucose level significantly decreased in KK-Ay mice after 3 weeks of PT. KK-Ay mice were known to belong to genetically-induced diabetes including ob/ob mice (11) and KK mice (12). KK-Ay mice show hyperinsulinemia as a result of insulin resistance

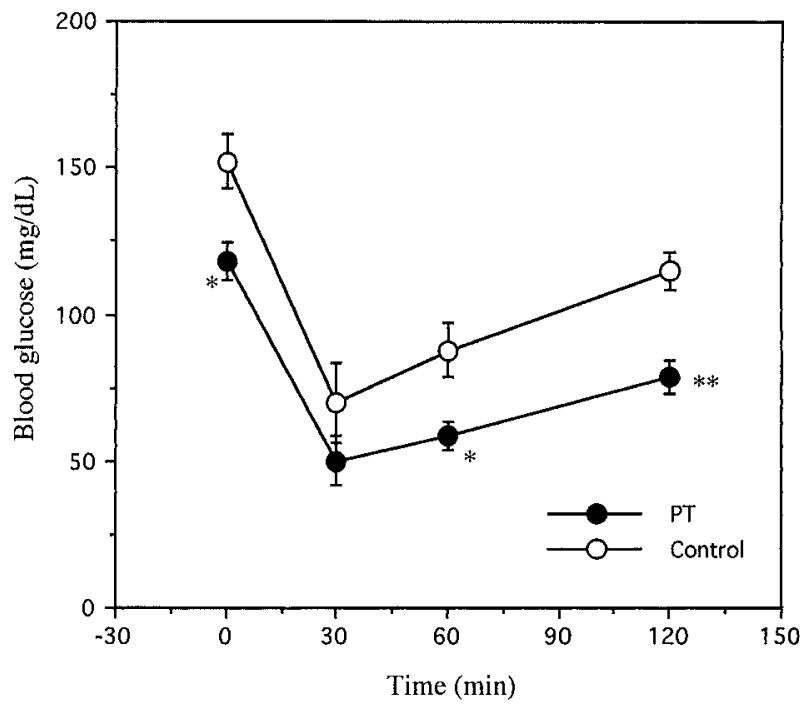

Fig. 2 Insulin tolerance test. KK-Ay mice were physically trained on a motorized treadmill for 120 $\min (5 \mathrm{~m} / \mathrm{min}, 7 \%$ grade). After 3 weeks, insulin $(0.5$ $\mathrm{U} / \mathrm{kg}$ ) were administered subcutaneously to KK-Ay mice after overnight fasting. Blood samples were taken for glucose determinations. Each point indicates the mean \pm S. E. M. from 3-4 mice. Significantly different from the control group, ${ }^{*} P<0.05,{ }^{*} P<<$ 0.01 . 


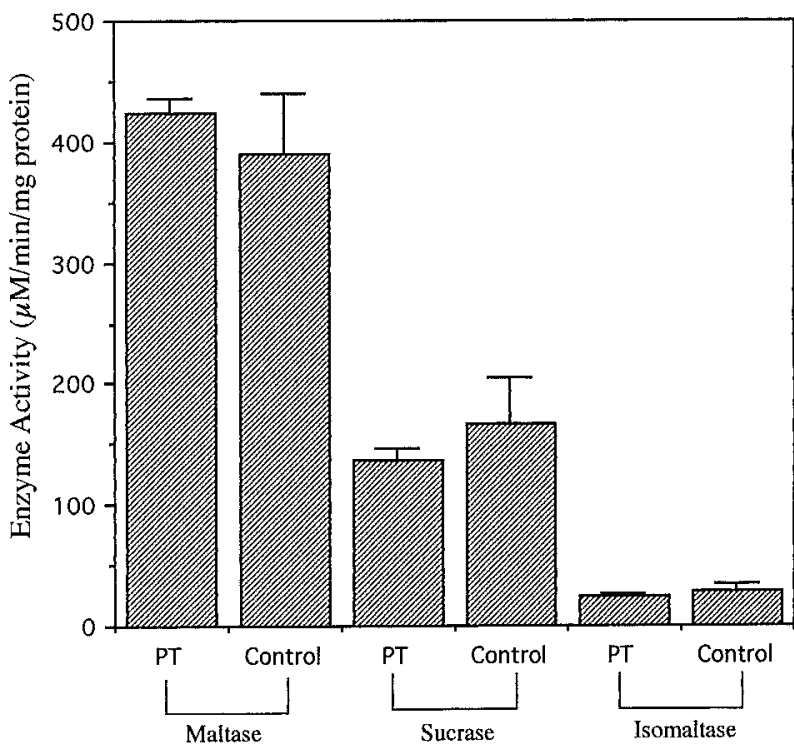

Fig. 3 Effect of PT on alpha-glucosidases activity in KK-Ay mice. KK-Ay mice were physically trained on a motorized treadmill for $120 \mathrm{~min}(5 \mathrm{~m} / \mathrm{min}, 7 \%$ grade). After 3 weeks of PT, alpha-glucosidase activity was measured. Each value indicates the mean \pm s. E. M. from 3-4 mice.

(3). PT showed lowered fasting blood glucose 3 weeks after (Fig. 2). In generally, it is shown that PT increases insulin sensitivity $(5,7)$. Our data is similar to them. We also studied the effect of PT on alpha-glucosidases. However, PT did not affect sucrase, maltase and isomaltase activity. On these results, the diatery cure of type 2 diabetes need not consider to elevate alpha-glucosidases activity by PT. We reported that, KK-Ay mice, alpha-glucosyldisaccharide digestive/absorptive capacity in small intestine was elevated (10). Increased alpha-glucosidases activity is one of the phathogenic factor in type 2 diabetes mellitus. The change of alpha-glucosidase activity affect gluocse absorption in small intestine. Therefore, it is important that PT did not affect the alphaglucosidase activity.

In generally, diabetes need long-term cure. Therefore, further studies will be needed to eluci- date the long-term effects. These results suggest the validity of clinical use of PT in the early stage of type 2 diabetes mellitus.

\section{REFERENCES}

1. Braun C., Brayer G. D., and Withers S. G. (1995) Mechanism-based inhibition of yeast alpha-glucosidase and human pancreatic alpha-amylase by a new class of inhibitors. J. Biol. Chem., 270, 26778-26781.

2. Caspary W. F., and Graf S. (1979) Inhibition of human intestinal alpha-glucoside hydrolase by a new complex oligosaccharide. Res. Exp. Med., 175, 1-6.

3. Coleman, D. L. (1982) Diabetes-obesity syndromes in mice. Diabetes, 31 (Suppl. 1), 1-6.

4. Dahlqvist A. (1964) A method for assay of intestinal disaccharidases. Anal. Biochem., 7, 18-25.

5. Davis, T. A. (1986) Glucose metabolism in opitrochlearis muscle of acutely exercised and trained rats. $A \mathrm{~m} . \mathrm{J}$. Physiol, 250, E137-E143.

6. Goda T., Yamada K., Hosaya N., and Moriuchi S. (1981) Effects of alpha-glucosidase inhibitor acarbose: fate and effects in man. Gastroenterology, 88, 1410.

7. Goodyear, L. J. (1990) Skeletal muscle plasma membrane glucose transport and glucose transporters after exercise. $J$. Appl. Physiol., 68, E193-E198.

8. Ho R. S., and Aranda C. G. (1983) Influence of acarbose on hyperglycemia induced by various carbohydrates in rats and oral starch tolerance in monkeys. Arch. Intern. Pharmcodynamics, 261, 147-156.

9. Jenkins D. J. A., Taylor R. H., Goff D. V., Fielden H., and Misisewicz J. J. (1981) Scope and specificity of acarbose in slowing carbohydrate absorption in man. Diabetes, $\mathbf{3 0}$, 951-954.

10. Miura T., Ishihara E., Ishida H., Seino Y., Tanigawa K. (1998) A genetic non-insulin dependent diabetic mice, $\mathrm{KK}$-Ay mice, is elevated alpha-glucosyldisaccharide digestive/absorptive capacity in small intestine. Biomedical Res., 19, 335-338.

11. Nakamura, M. (1962) A diabetic strain of the mouse. Proc. Jpn. Acad., 38, 348-352.

12. Nishimura, M. (1969) Breeding of mice strains for diabetic mellitus. Exp. Animal, 18, 147-157.

13. Radziuk J., Kemmer F., Morishima T., Berchtold P., and Vranic M. (1984) The effects of an alpha-glucoside hydrolase inhibitor on glycemia and absorption of sucrose in man determined using a tracer method. Diabetes, 33, 207-213.

14. Stevens J. F. (1951) Detarmination of blood glucose oxidase method. Clin. Chim. Acta. 32, 199-201.

15. Taylor R. H., Jenkins D. J. A., Barker H. M., Fielden H., and Goff D. V. (1982) Effect of acarbose on the 24-hour blood glucose profile and pattern of carbohydrate absorption. Diabetes Care, 5, 92-96. 